\title{
Characterization of a Mycobacterium smegmatis uvrA mutant impaired in dormancy induced by hypoxia and low carbon concentration
}

\author{
Angela Cordone ${ }^{1,2^{*}}$, Bianca Audrainn ${ }^{2,3}$, Immacolata Calabrese ${ }^{1}$, Daniel Euphrasie ${ }^{2}$ and Jean-Marc Reyrat ${ }^{2}$
}

\begin{abstract}
Background: The aerobic fast-growing Mycobacterium smegmatis, like its slow-growing pathogenic counterpart Mycobacterium tuberculosis, has the ability to adapt to microaerobiosis by shifting from growth to a nonproliferating or dormant state. The molecular mechanism of dormancy is not fully understood and various hypotheses have been formulated to explain it. In this work, we open new insight in the knowledge of $M$. smegmatis dormancy, by identifying and characterizing genes involved in this behavior.

Results: In a library generated by transposon mutagenesis, we searched for M. smegmatis mutants unable to survive a coincident condition of hypoxia and low carbon content, two stress factors supposedly encountered in the host and inducing dormancy in tubercle bacilli. Two mutants were identified that mapped in the uvrA gene, coding for an essential component of the Nucleotide Excision Repair system (NER). The two mutants showed identical phenotypes, although the respective transposon insertions hit different regions of the uvrA gene. The restoration of the UvrA activity in $M$. smegmatis by complementation with the UvrA gene of $M$. tuberculosis, confirmed that i) UVrA inactivation was indeed responsible for the inability of $M$. smegmatis cells to enter or exit dormancy and, therefore, survive hypoxia and presence of low carbon and ii) showed that the respective uvrA genes of $M$. tuberculosis and $M$. smegmatis are true orthologs. The rate of survival of wild type, uvrA mutant and complemented strains under conditions of oxidative stress and UV irradiation was determined qualitatively and quantitatively.
\end{abstract}

Conclusions: Taken together our results confirm that the mycobacterial NER system is involved in adaptation to various stress conditions and suggest that cells with a compromised DNA repair system have an impaired dormancy behavior.

\section{Background}

Mycobacterium tuberculosis, the etiological agent of tuberculosis, has the ability to enter human macrophages and survive inside them in a 'latent' or 'non-proliferating' form for a long period of time. This behavior is termed dormancy or latency. During their lifetime, latent bacilli can reactivate giving rise to active tuberculosis, the transmissible form of the disease [1-3].

The molecular mechanism allowing dormancy is not fully understood due the lack of experimental systems that can closely mimic human latent infections [1]. In

\footnotetext{
* Correspondence: angelina.cordone@unina.it

'Dipartimento di Biologia Strutturale e Funzionale, Università Federico II di

Napoli, via Cinthia 4, 80126 Napoli, Italy

Full list of author information is available at the end of the article
}

the granuloma, dormancy is hypothesized to occur in response to low oxygen, stress and lack of nutrients [1].

Experimental evidences suggest that, within the granuloma, the in vivo environment where dormant mycobacteria persist, the oxygen concentration is the limiting factor for bacterial growth and the condition that induces dormancy. Therefore, during the last few years, various experimental models using microaerobiosis or anaerobiosis, have been developed to reproduce dormancy in vitro [4-6]. There is also evidence that tubercle bacilli suffer nutrient deprivation in lung lesions [7]. Conditions of nutrient limitation have been used to investigate the ability of $M$. tuberculosis to persist in a non-growing state for long periods of time [7-9]. Importantly, dormancy is a common behavior to both
C Biomed Central 
pathogenic and non-pathogenic mycobacteria, in vitro $[4,10,11]$, allowing the study of pathogenic species by using non-pathogens as model.

M. smegmatis is a fast growing non pathogenic mycobacterium frequently used as a model system to study its pathogenic counterpart M. tuberculosis. M. smegmatis becomes dormant in low oxygen concentration conditions [5] and remains viable for over 650 days when it suffers carbon, nitrogen and phosphorous-starvation [12]. Based on these observations, we decided to use low oxygen and limiting nutrient conditions to develop an in vitro system. Then, we used such system to screen a library of $M$. smegmatis generated by insertion mutagenesis and look for mutants defective in dormancy [13]. This strategy allowed the isolation of two mutants with insertions mapping in the $u v r A$ gene. The UvrA protein belongs to the nucleotide excision repair system (NER) and is highly conserved among mycobacteria. NER counteracts the deleterious effects of DNA lesions acting as an endonuclease enzyme complex including four Uvr proteins: UvrA, UvrB, UvrC, and UvrD. UvrA, togheter with UvrB, plays a key role in the recognition of DNA damaged sites [14]. UvrC, together with UvrB, perform a single strand incision at both sides of the damaged site and the DNA fragment is removed by the action of the UvrD helicase.

While this DNA-repair system has been largely analyzed in E. coli [14], it remains poorly characterized in mycobacteria. It has been recently reported that the $M$. smegmatis genome is predicted to encode two additional UvrA proteins, named UvrA2 and UvrA-like protein, whose function are still unknown [15].

Here we report that the M. smegmatis UvrA protein is essential for the mycobacterial dormancy behavior and survival in hostile growth conditions, such as low oxygen and carbon content, also observed in the granuloma. Our results, together with recent analyses [16-19], suggest that the NER system plays a key role in $M$. smegmatis dormancy.

\section{Results}

M. smegmatis dormancy is induced under conditions of low oxygen and low carbon availability

In order to develop a simple and reliable strategy to screen a M. smegmatis library for mutants unable to grow in conditions of hypoxia and low carbon concentration, we first compared the effects of these conditions on the dormancy behavior of M. smegmatis wt and ppk1- mutant cells [the latter were used as a control as they have been recently reported to be sensitive to hypoxic condition [20]]. To assess whether low carbon availability represented a limiting factor, we analyzed the effect of different glucose concentrations on $M$. smegmatis growth rate. To this purpose, wt and ppk1 strains were grown at $37^{\circ} \mathrm{C}$ in minimal medium containing glucose as the only carbon source at the following final concentrations: $0.4 \% ; 0.2 \%$ or $0.01 \%(\mathrm{w} / \mathrm{v})$. The growth rate was monitored for 35 hours by measuring the $\mathrm{OD}_{600 \mathrm{~nm}}$. As shown in Figure $1 \mathrm{~A}$, when the minimal medium was supplemented with glucose $0.4 \%(\mathrm{w} / \mathrm{v})$, cultures entered stationary phase at an $\mathrm{OD}_{600 \mathrm{~nm}}$ of 2.4, whereas using glucose $0.2 \%(\mathrm{w} / \mathrm{v})$, stationary phase was entered at 1.1 OD. When an even lower glucose concentration $(0.01 \% \mathrm{w} / \mathrm{v})$ was added to the medium, cells growth was inhibited, indicating that the arrest of cell growth was due to carbon starvation. Similar results were obtained for the $p p k$ mutant (data not shown). These results indicate that the M. smegmatis growth rate is significantly limited by the amount of carbon source. Based on this, we decided to use a glucose concentration of $0.2 \%$ for the further analyses. Next, we analyzed the effect of hypoxia on dormancy by following the bacterial cell growth up to $1.0 \mathrm{OD}$ in the presence of $0.2 \%$ gluscose. Serial dilutions of wt and $p p k 1$ strains were transferred to agar plates and incubated in either atmosphere oxygen concentration or anaerobic
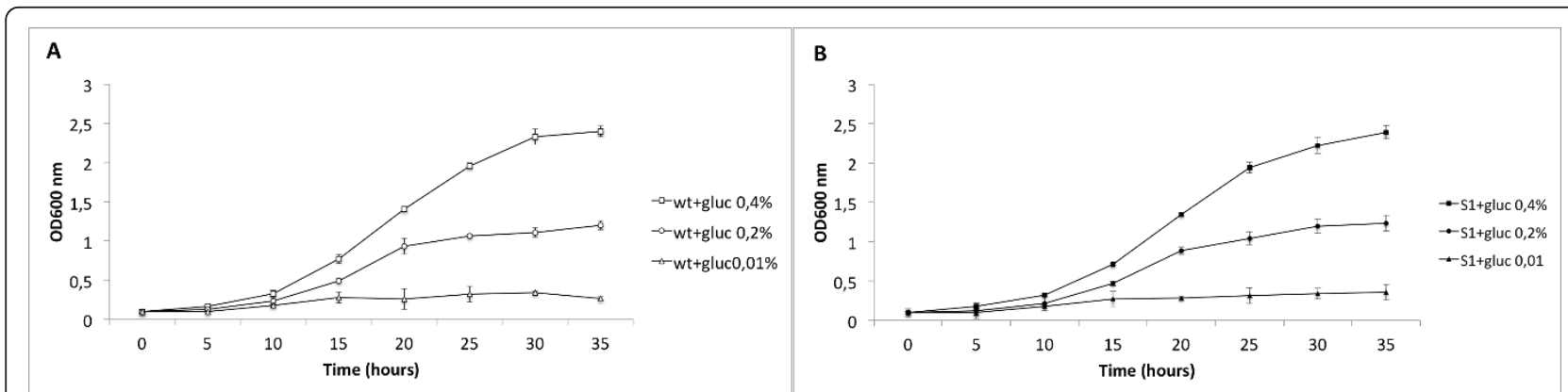

Figure 1 Effect of nutrient limitation on $\mathbf{M}$. smegmatis growth. (A) M. smegmatis wild type and (B) S1 strains were grown in M9 minimal medium supplemented with glucose at the final concentration of $0.4 \%$ (wt, white square; S1, black square); $0.2 \%$ (wt, white circle; S1, black circle) or $0.01 \%$ (wt, white triangle; S1, black triangle). The growth rate was monitored for 35 hours by measuring $\mathrm{OD}_{600 \mathrm{~nm}}$. For each strain the data reported in graph represent the mean of three independent experiments. 
conditions in jar $\left(<1 \% \mathrm{O}_{2}\right)$. Bacterial cell growth of both wt and $p p k 1$ strains, resulted unaffected in aerobic conditions, for as long as 4-5 days of incubation. However, the cell growth of the two strains resulted completely inhibited in anaerobic conditions for at least 14 days, indicating that low oxygen is an inhibitory factor. After 14 days of growth in anaerobic conditions, the same plates containing wt and ppk1 cells were incubated in normal oxygen condition for 4-5 day. As represented in Figure 2A, M. smegmatis wild type cells show restored cell growth without a significant cell loss, when exposed to oxygen. This result indicates that wt cells are able to exit the dormant state and restore cell growth. In contrast, $p p k-1$ cells showed only a $40 \%$ of restored cell growth in compared to wt (data not shown), suggesting that this strain is unable to either enter or exit the dormant state. These results allow us to conclude that our experimental system represents a valuable platform to screen the M. smegmatis transposon library.

\section{Library screening and isolation of $M$. smegmatis mutants with impaired dormancy behavior upon hypoxia and low carbon availability}

Ten thousand clones of a transposon library containing more than 20,000 mutants and covering the majority of the M. smegmatis gene pool [13] were screened as

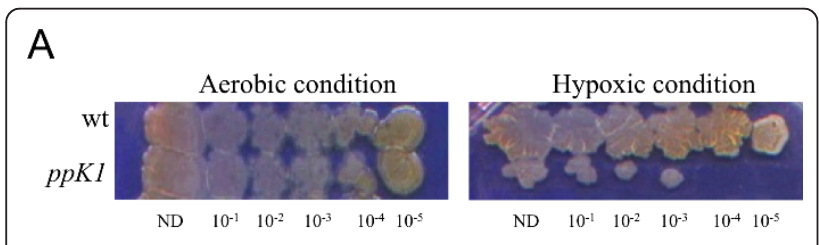

B
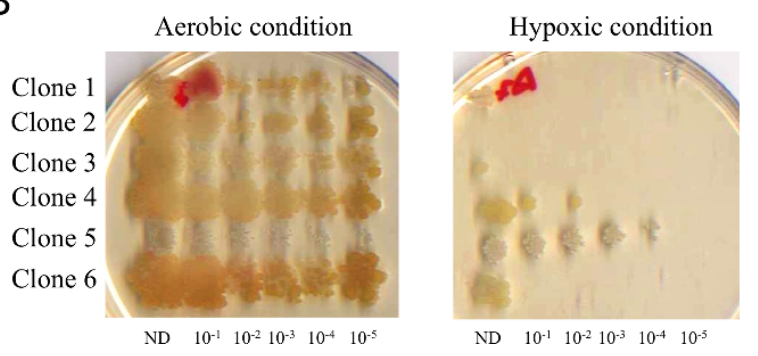

Figure 2 Screening of $\boldsymbol{M}$. smegmatis mutant library. A) (Left panel) M. smegmatis wild type and ppk mutant were grown in M9 minimal medium supplemented with glucose $0.2 \%$ until OD $_{600 \mathrm{~nm}}=$ 1.0 , serially diluted up to $10^{-5}$ and transferred by using a metal replicator on agar plates. (Right panel) After incubation at $37^{\circ} \mathrm{C}$ for 4-5 days for aerobic cultures, or incubation for 2 weeks in an AnaeroGen gas pack system at $37^{\circ} \mathrm{C}$ followed by incubation under aerobic condition at $37^{\circ} \mathrm{C}$ for $4-5$ days, plates were compared. B) Individual screening of 6 selected mutants. Each clone was grown in M9 minimal medium supplemented with glucose $0,2 \%$ until $\mathrm{OD}_{600 \mathrm{~nm}}=1.0$, serially diluted up to $10^{-5}$ and transferred by using a metal replicator on agar plates. Clones 1, 3 and 6 were considered as moderately affected clones. Clone 2 was considered as severely affected. ND = Non Diluted culture described above to isolate mutants unable to survive a prolonged exposure to low oxygen tension and low carbon availability. The screening allowed us to isolate a total of 278 insertion mutants unable to survive these conditions. Each clone was serially diluted to further confirm the observed phenotype (see a 6-clone sample plate in Figure 2B). During individual screening, 21 clones sensitive to hypoxia and low carbon availability were isolated and divided in two groups: the first group included 8 clones that were completely unable to survive and, therefore, defined as severely affected (S); the second group included the remaining 13 clones that were only partially affected and, therefore, defined as moderately affected (M) (Figure 2B). Most likely, these mutants are unable to either enter or exit the dormant state.

In order to identify the sites of transposon insertions, the genomic DNA of all clones was extracted, digested with the SalI restriction enzyme and used as template in Ligated Mediated (LM)-PCR reactions [21]. Using this approach, we were able to map the site of transposon insertion of $13 \mathrm{M}$ mutants and $3 \mathrm{~S}$ mutants (Table 1 ). In two independent mutants, here named S1 and S2, the transposon insertion mapped in different positions of the $u v r A$ gene (Table 1). The $u v r A$ gene encodes the UvrA protein that belongs to the nucleotide excision repair system (NER). As the two mutants showed identical phenotypes, S1 was chosen for further characterization.

\section{UvrA is important for mycobacterial dormancy and survival upon hypoxia}

To verify whether the severe dormancy defect of the uvrA mutants in our in vitro model system was a direct effect of UvrA deficiency, we performed complementation analyses. A wild type allele of the $u v r A$ gene was PCR-amplified, cloned into the integrative expression vector pNip40-b [22] and electroporated into the S1 mutant strain. The resulting strain was analyzed for its phenotype. As shown in Figure 3, the reintroduction of a single copy of $u v r A$ from $M$. smegmatis (here defined as S1-uvrA-Ms) fully restored the dormancy defect of the parental mutated strain. Identical results were obtained for the S2 mutant (data not shown).

As shown in Table 1, a BLAST search performed using $u v r A$ of $M$. smegmatis as a query showed that this gene is highly conserved in M. tuberculosis. The orthology between the M. smegmatis and M. tuberculosis UvrA proteins was verified by using the $M$. tuberculosis uvrA gene to complement the M. smegmatis uvrA deficient strain (Figure 3). The reintroduction of the $M$. tuberculosis uvrA wt gene (here defined as S1-uvrA-Tb) was able to restore the wt phenotype in the M. smegmatis mutated strain. Our results demonstrate that UvrA is 
Table 1 Genes disrupted in M and S mutants identified ( LM)-PCR

\begin{tabular}{|c|c|c|c|c|}
\hline $\begin{array}{l}\text { Clone } \\
\text { name }^{3}\end{array}$ & $\begin{array}{l}\text { M. smegmatis } \\
{\text { mc } 2155^{\mathrm{b}}}\end{array}$ & Gene product/function & $\begin{array}{l}\text { Insertion } \\
\text { site }^{c}\end{array}$ & M. Tuberculosis ortholog(\% identity) \\
\hline $\mathrm{Ml}$ & MSMEG_4806 & putative acyl-CoA & 201 & $\mathrm{NF}^{\mathrm{e}}$ \\
\hline M2 & MSMEG6781 & hypothetical protein & 681 & NF \\
\hline M3 & MSMEG_4727 & Mycocerosic Acid synthase & 2723 & Rv1527(65\%) \\
\hline M4 & MSMEG_6215 & Manganese containing catalase & 252 & NF \\
\hline M5 & MSMEG_5925 & Riesce(2Fe-2S) domain protein & 608 & Rv3526 (65\%) \\
\hline M6 & MSMEG_3215 & ABC transporter ATP-binding protein & 518 & NF \\
\hline M7 & MSMEG_5714 & Short-chain dehydrogenase/reductase SDR & 104 & NF \\
\hline M8 & MSMEG_0200 & Hypotetical protein & 779 & NF \\
\hline M9 & MSMEG_6105 & Cell division protein & 447 & Rv3610c (86\%) \\
\hline M10 & MSMEG_0831 & Short-chain dehydrogenase & 159 & NF \\
\hline Mil & MSMEG_6611 & Hypotetical protein & 110 & NF \\
\hline M12 & MSMEG_0304 & Acyl-CoA synthase & 177 & Rv1427c (77\%) \\
\hline M13 & MSMEG_0228 & $\begin{array}{l}\text { Adenylate and Guanilate cyclase domain } \\
\text { protein }\end{array}$ & 1417 & NF \\
\hline $\mathrm{SI}$ & MSMEG_3808 & UvrA exinuclease, $A B C$, A subunit & 866 & Rv1638 (88\%) \\
\hline S2 & MSMEG_3808 & UvrA exinuclease, $A B C$, A subunit & 959 & Rv1638 (88\%) \\
\hline S3 & MSMEG_4293 & Glutammate-ammonia-ligase adenylyltransferase & 883 & Rv2221c(73\%) \\
\hline
\end{tabular}

${ }^{\mathrm{a}}$ Selected mutants moderately (M) or severely affected (S)

${ }^{\mathrm{b}}$ Genes are indicated as annotated by TIGR/GeneBank database (Accession number C000480.1)

${ }^{\mathrm{c}}$ Relative to the first base of the putative coding sequence

${ }^{\mathrm{d}}$ Cut off identity was set at $60 \%$

e Not found

essential for $M$. smegmatis to enter or exit dormancy upon hypoxia. Moreover, we proved that the M. smegmatis and $M$. tuberculosis gene products are true orthologs.

UvrA deficiency does not influence $M$. smegmatis growth under nutrient limiting conditions

In addition to hypoxia, nutrient starvation is also supposed to affect cell growth. To check whether the NER

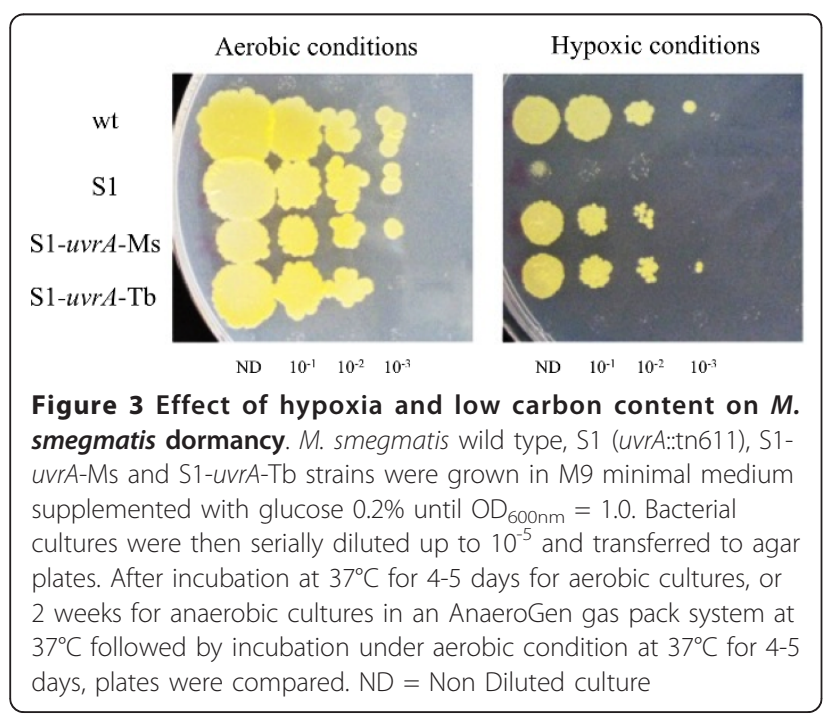

deficiency had an effect on cell growth in nutrient limitation, we monitored the growth rate of the $u v r A$ mutant and the complemented strains in minimal medium supplemented with the following final glucose concentration: $0.4 \% ; 0.2 \%$ or $0.01 \%(\mathrm{w} / \mathrm{v})$. As shown in Figure $1 \mathrm{~B}, u v r A$ mutant cells grown in $0.2 \%$ glucose entered stationary phase at a lower optical density $\left(\mathrm{OD}_{600 \mathrm{~nm}} \approx 1.1\right)$ in compared to cells of the same strains grown in higher $(0.4 \%)$ glucose concentration. Moreover, both wt and $u v r A$ cell growth arrested at the limiting glucose concentrations $(0.01 \%)$. Taken together these results indicate that $M$. smegmatis growth rate is limited by the amount of carbon available and also that absence of UvrA does not affect $M$. smegmatis growth under nutrient-limited conditions.

The mycobacterial NER system is involved in the protection from UV-induced damage of DNA

The NER system has been extensively studied in E. coli where the $u v r$ gene products protect bacteria from different types of DNA damages including those induced by UV radiations [14]. To verify whether the NER system had a similar function in mycobacteria, we measured the effect of UV light exposure on wild type, uvrA (S1), the complemented derivatives of this mutant, containing the uvrA gene from $M$. smegmatis (S1-uvrA-Ms) and $M$. tubercolosis (S1-uvrA-Tb), respectively. As shown in Figure $4 \mathrm{~A}$, while $u v r A$ cells were unable to grow after a 15 


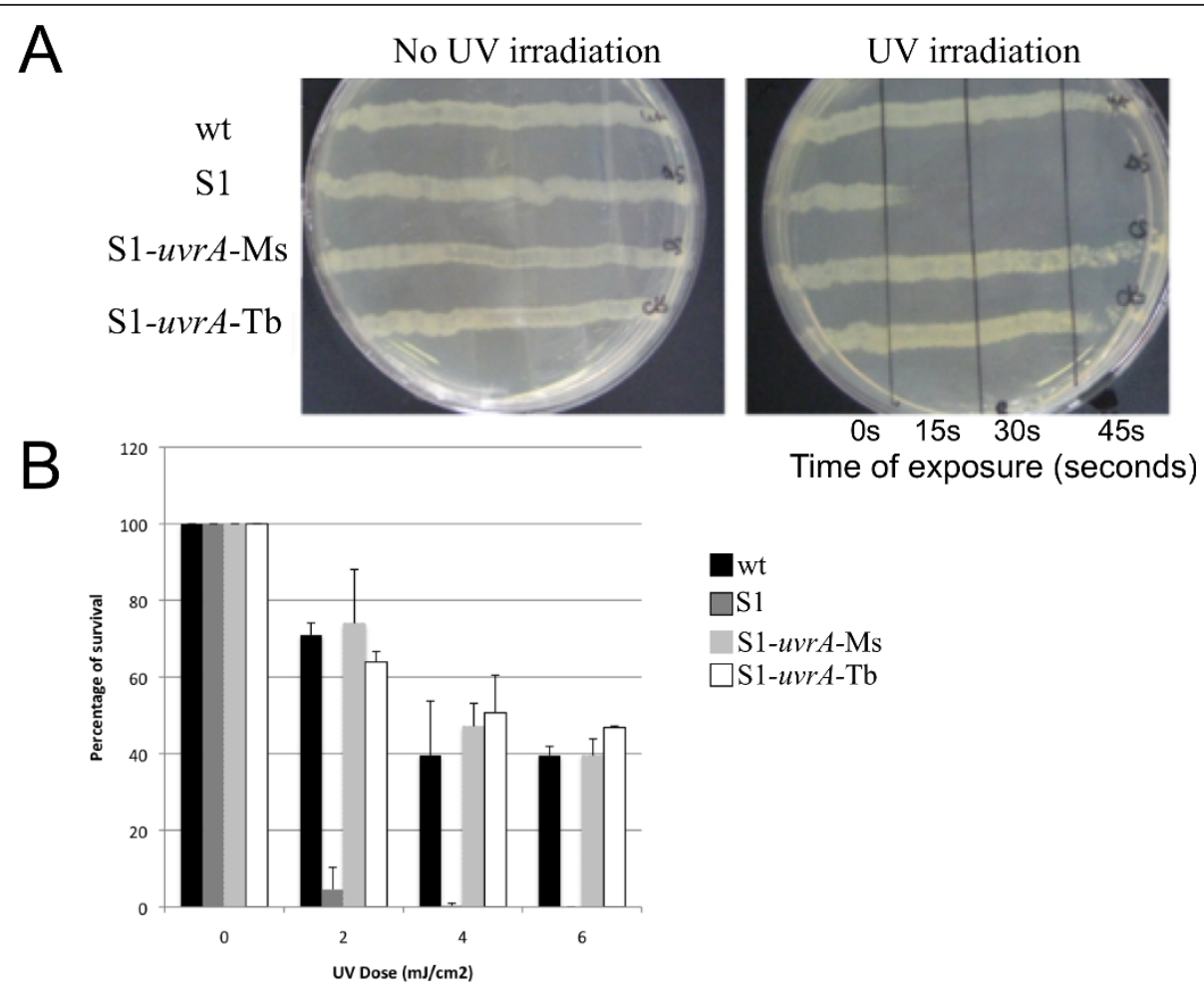

Figure 4 UV irradiation assay. A) M. smegmatis wild type, S1 (uvrA::tn611), S1-uvrA-Ms and S1-uvrA-Tb strains were streaked from left to right on LB plates. Plates were either exposed or not to UV radiation (0, 15, 30 and 45 seconds). B) M. smegmatis wild type, S1, S1-uvrA-Ms and S1uvrA-Tb cells in exponential phase were harvested and resuspended in PBS (see Methods for details). Aliquots were exposed to different UV doses $\left(0,2,4\right.$ and $\left.6 \mathrm{~mJ} / \mathrm{cm}^{2}\right)$. The percentage of survival of each strain was determined and represented as the mean value of three independent experiments.

sec exposure to UV light $(\lambda=254 \mathrm{~nm})$, the wild type and the complemented strains were unaffected by the treatment. To further verify the importance of UvrA in preventing UV-induced DNA damages, all strains were exposed to different UV light doses. As shown in Figure $4 \mathrm{~B}$, the S1 strain showed a marked sensitivity to UV irradiation with only $7 \%$ survival after exposure to $2 \mathrm{~mJ} / \mathrm{cm}^{2}$ $\mathrm{UV}$, whereas the wild type and both complemented strains showed a comparable dose-dependent sensitivity to UV irradiation with more than $60 \%$ survival after exposure to the same UV dose. Taken together these results suggest that $M$. smegmatis $\mathrm{UvrA}$ is involved in the repairing of UV-induced DNA damages as reported for other bacteria [14].

\section{The UvrA NER system contributes to repair DNA oxidative damages}

It is hypothesized that inside the granuloma, dormant bacilli are continuously exposed to reactive oxygen species (ROS) and Reactive Nitrogen Intermediates (RNI) [23-27], lipo-soluble molecules that can enter the mycobacterial waxy cell wall, thus causing DNA damages.

To better clarify the role of the NER system in oxidative stress, we determined the effect of oxidative stress on wt, $u v r A$ mutant S1 and complemented strains S1uvrA-Ms and S1-uvrA-Tb cell growth. To this purpose, cells were incubated in the presence of $5 \mathrm{mM} \mathrm{H}_{2} \mathrm{O}_{2}$ and growth $\left(\mathrm{OD}_{600 \mathrm{~nm}}\right)$ was monitored at 3 hours intervals for $48 \mathrm{~h}$. As shown in Figure 5A, the uvrA mutant strain, in contrast to wild type and complemented strains, stopped growing after three mass doubling time in the presence of hydrogen peroxide. The $u v r A$ mutant strain reached a maximal cell density of $8 \times 10^{6}$ c.f.u. $\mathrm{ml}^{-1}$, which was approximately 4 -fold higher than the density of the initial inoculum $\left(2 \times 10^{6}\right.$ c.f.u. $\left.\mathrm{ml}^{-1}\right)$ but 1000 -fold less than the density of the wild-type and the two complemented strains $\left(8 \times 10^{9}\right.$ c.f.u. $\left.\mathrm{ml}^{-1}\right)$. Interestingly, the growth curve of the two complemented strains shows a lag-phase under normal growth conditions (Figure $5 \mathrm{~B}$ ) that it is not observed when bacteria are exposed to oxidative stress (Figure 5A). This result is probably due to the fact that, in the complemented strains, the $u v r A$ gene is not expressed under the regulation of endogenous promoter region. Our results suggest that mycobacteria need a functional NER system to neutralize the damaging effects of oxyradicals, emphasizing once again the importance of the NER system for mycobacterial survival under stress conditions. 


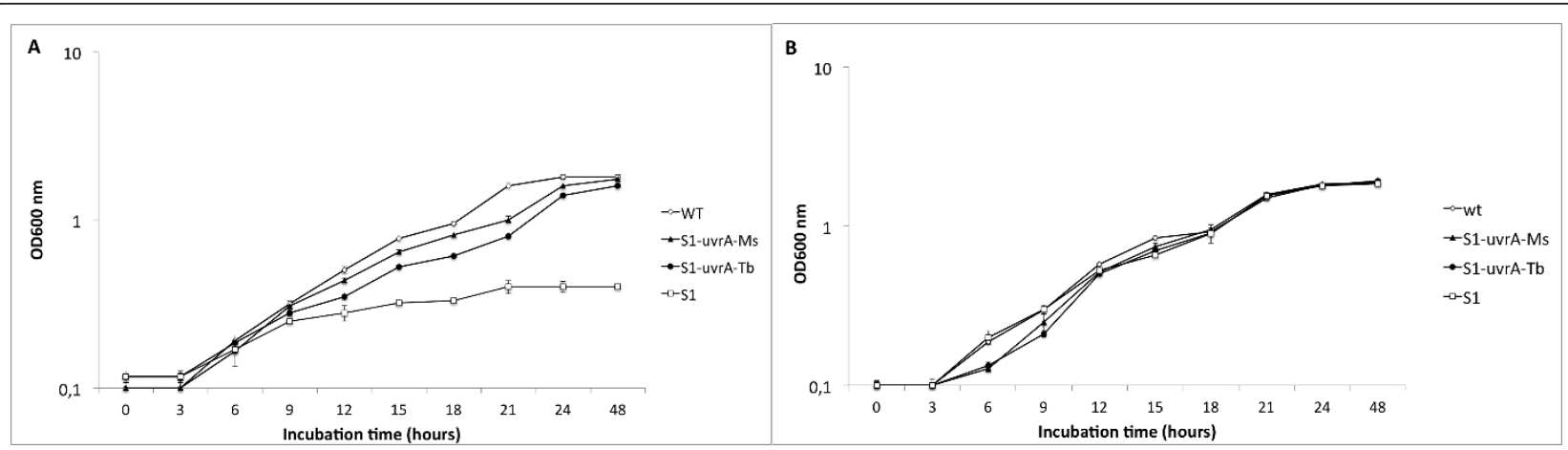

Figure 5 Effect of hydrogen peroxide on cell growth. M. smegmatis cells of wild type, S1, S1-uvrA-Ms and S1- uvrA-Tb strains were grown in LBT with (A) or without (B) $5 \mathrm{mM} \mathrm{H} \mathrm{O}_{2}$ and $\mathrm{OD}_{600 \mathrm{~nm}}$ determined every 3 hours. For each strain the data reported in graph is the mean of three independent experiments.

\section{Discussions}

In silico analysis of mycobacterial genomes [28] has shown the presence of genes encoding enzymes involved in different DNA repair system such as Nucleotide Excision Repair (NER), Base Excition Repair (BER), Recombinational Repair, Non-Homologous End-joining repair and SOS repair. Surprisingly, even if mycobacteria lack the $m u t S L$-based post-replicative mismatch repair system [29], their mutation rate is similar to those of other bacteria [30]. A recent analysis provided evidence that the mycobacterial NER system is able to repair a wider range of DNA damages than the corresponding E. coli system, highlighting its involvement in mismatch recognition and suggesting a crucial role of the NER system in preserving the mycobacterial genome integrity $[16,19]$. Although mycobacterial DNA repair systems are still not well characterized [31], it is possible that their functions are important for survival of tubercle bacilli during latency. Latent mycobacteria, in fact, are continuously exposed to the action of compounds such as Reactive Oxygen Species (ROS) and Reactive Nitrogen Intermediates (RNI) that induce DNA damage [24-27]. The deleterious effects of these intermediates, is probably counteracted by the synergic action of highly efficient and functional DNA repair systems. Oxidative stress results in different types of non-bulky DNA damages such as formation of abasic sites, single and double-stranded breaks, or production of oxidized bases converting guanine to 7,8-dihydro-8-oxoguanine. Although Base Excision Repair (BER) is the main pathway for the removal of this kind of lesion [32-34], we hypothesized that during dormancy the BER system is overwhelmed by extensive DNA damages and that mycobacterial genome integrity might be preserved by a synergic action of different DNA repair systems among which NER. Earlier studies have shown that a M. tuberculosis NER-deficient strain mutated in $u v r B$, is markedly attenuated for survival in mice and that UvrB protein is required for resistance of $M$. tuberculosis to both ROS and RNI species in vivo [17]. It has also been recently reported that a $M$. smegmatis $u v r B$ mutant is sensitive to stress factors such as hypoxia, a condition under which bacteria are not proliferating thus they can accumulate DNA damage over time [18].

In this study we used hypoxia and low carbon availability as a model for dormant state to screen a library of M. smegmatis insertional mutants. This strategy led to the isolation of two strains mutated in the $u v r A$ gene and unable to survive such condition. We showed that the M. smegmatis UvrA protein is essential to survive the in vitro dormancy condition of growth. Moreover, we demonstrated that the UvrA protein is needed for cell to neutralize both UV light- and oxyradicalsinduced damages.

According to these data, it is possible to hypothesize that the uvrA mutant is not able to survive the in vitro dormancy conditions because of sudden oxygen increase following the opening of the jars. The oxidative burst created is probably neutralized by the synergic action of functional DNA repair systems, which maintain the genome integrity. A deficiency in one of the DNA repair systems during this step may result in the accumulation inside the mycobacterial genome of mutations which are not counteracted by the action of the remaining repair systems, resulting in failure of cells to reactivate.

A future analysis of the $M$. tuberculosis uvrA knockout mutants using human macrophages and mouse infection as an in vitro and in vivo dormancy model systems will give more insight into mycobacterial survival during latency and will help to better clarify the importance of $M$. tuberculosis NER system during latency.

\section{Conclusions}

In this report we describe the isolation and subsequent analysis of a $M$. smegmatis strain mutated in the $u v r A$ gene under different stress conditions. 
We demonstrate that M. smegmatis UvrA deficient strain is more sensitive to hypoxia, UV radiation and oxidative stress than wild type and that the use of $M$. smegmatis own gene or the corresponding $M$. tuberculosis homologous gene, fully restore the wild type ability to resist these factors.

Based on our data, we can conclude that UvrA protein, and thus the NER system, is an importatnt player for adaptation of M. smegmatis to various stress conditions. Further analysis are needed to better clarify the role of NER system in the complex phenomenon of mycobacterial dormancy.

\section{Methods}

Bacterial strains, media and growth conditions

Mycobacterium smegmatis $\mathrm{mc}^{2} 155$ [35] is the parental of all the recombinant strains described below. E. coli DH5 $\alpha$ strain (supE44 AlacU169 [ $880 \Delta$ lacZM15] hsdR17recA1) [36] was used for all cloning experiments.

M. smegmatis $\mathrm{mc}^{2} 155$ and derivatives were grown in LB medium containing 0,05\% Tween 80 (LBT).

For nutrient limitation experiments, $M$. smegmatis $\mathrm{mc}^{2} 155$ and derivatives were grown in M9 containing 1 $\mathrm{mM} \mathrm{Mg} \mathrm{SO}_{4}$ and supplemented with glucose at the following final concentrations: $0.4 \% ; 0.2 \%$ or $0.01 \%(\mathrm{w} / \mathrm{v})$.

Escherichia coli strains were grown in LB medium. When required, antibiotics were added to the medium at the following final concentrations: ampicillin $100 \mu \mathrm{g} /$ $\mathrm{ml}$, kanamycin $25 \mu \mathrm{g} / \mathrm{ml}$. Hygromicin was used at 200 $\mu \mathrm{g} / \mathrm{ml}$ for $E$. coli and $50 \mu \mathrm{g} / \mathrm{ml}$ for $M$. smegmatis.

\section{In vitro dormancy assay}

M. smegmatis transposon insertion mutants [13] were thawed and printed by using a metal replicator in 96 well plates in $\mathrm{M} 9$ medium containing $1 \mathrm{mM} \mathrm{Mg}_{2} \mathrm{SO}_{4}$ and $0.2 \%$ glucose at $37^{\circ} \mathrm{C}$ in standing condition until $\mathrm{OD}_{600} \mathrm{~nm}=$ 1.0. After incubation time, wild type and mutant strains were serially diluted 1:10 up to $10^{-5}$ and spotted on M9 agar plates containing glucose. Control plates were incubated in normal atmosphere $\left(20 \% \mathrm{O}_{2}\right)$ for $4-5$ days at $37^{\circ}$ $\mathrm{C}$, whereas experimental plates were transferred to anoxic jar (Oxoid) for 2 weeks at $37^{\circ} \mathrm{C}$. Hypoxia was generated using AnaeroGen gas pack system (Oxoid) inside jars and anaerobiosis $(\mathrm{O} 2<1 \%)$ was checked by using methylene blue as indicator. Plates were finally removed from the anoxic jar and incubated in normal atmosphere to enable growth of the surviving bacteria.

\section{DNA manipulation}

Plasmid and chromosomal DNA preparation, restriction digestion, ligation, bacterial transformation and agarose gel electrophoresis were performed as described [36,37]. For complementation analyses, $u v r A$ genes from $M$. smegmatis mc2 155 and M. tuberculosis H37Rv were
PCR amplified as follow: the wild-type uvrA gene from M. smegmatis $\mathrm{mc}^{2} 155$ was amplified by PCR with Pfu Turbo high fidelity DNA polymerase (Stratagene) by using chromosomal DNA as a template and oligos uvrA-Ms-F and uvrA-Ms-R (Table 2) as primers. Both primers contain an engineered $\mathrm{XbaI}$ restriction site. After purification with the PCR purification Qiagen kit, PCR products were digested with $\mathrm{XbaI}$ and cloned into the dephosphorylated integrative expression vector pNIP40b [22] at the unique XbaI site to generate pNIPuvrA-Ms. As previously reported, cloning a gene at this site in pNip40b leads to a transcriptional fusion with an upstream promoter and expression of the transgene $[38,39]$. One clone was selected and sequenced. Plasmid pNip-uvrA-Tb was obtained using a similar strategy. Chromosomal DNA of M. tuberculosis H37Rv was amplified using primers uvrA-Tb-F and uvrA-Tb-R and Pfu Turbo high fidelity DNA polymerase (Stratagene). PCR product was purified with the PCR purification Qiagen kit, digested with $\mathrm{XbaI}$ and ligated into the pNIP40b at the unique XbaI site. One clone was selected and sequenced. These plasmids were electroporated into the $M$. smegmatis uvrA mutant strain S1 (uvrA ::Tn611) and transformants were selected on hygromicin containing LB plates and named S1-uvrAMs and S1-uvrA-Tb.

\section{Ligation-mediated PCR (LM-PCR)}

Transposon insertions were mapped by using LM-PCR as previously reported [21]. LM-PCR reactions were done using SalI and BamHI enzymes (Roche). PCR products were separated by $1.5 \%$ agarose gel and the fragments were purified using QIAquick gel extraction kit (Qiagen). The purified fragments were used as templates in sequencing reactions together with oligonucleotide $\mathrm{F}$ or G [20].

\section{UV irradiation assay}

M. smegmatis strains were grown in LBT medium up to exponential phase $\left(\mathrm{OD}_{600 \mathrm{~nm}}=0.4-0.6\right)$. Samples from

\section{Table 2 Synthetic oligonucleotides}

\begin{tabular}{lll}
\hline Name & Sequence $\left(\mathbf{5}^{\prime}-\mathbf{3}^{\prime}\right)^{\mathbf{a}}$ & $\begin{array}{c}\text { Position of } \\
\text { annealing }\end{array}$ \\
\hline $\begin{array}{l}\text { UvrA- } \\
\text { Ms-Y }\end{array}$ & ctagtctagagacgtgtccggtgtaggtgt & $-180 /-160$ \\
$\begin{array}{l}\text { UvrA- } \\
\text { Ms-R }\end{array}$ & ctagtctagaatgacctggtggatcgactg & $+150 /+169$ \\
uvrA- & ctagtctagacgatgccttgaggatcgtg & $-258 /-240$ \\
Tb-F & & \\
UvrA- & ctagtctagagaagatcgaaacccgatacg & $+194 /+213$ \\
Tb-R & & \\
\hline
\end{tabular}

${ }^{a}$ Underlined is an unpaired tail carrying $X b a l$ restriction site. ${ }^{b}$ Position of annealing refers to the $u v r A$ gene sequence, with the first base of the translational initiation codon as +1 . 
these cultures were streaked on LB agar plates. Plates were exposed to UV light during $0,15,30$ and 45 seconds and then incubated at $37^{\circ} \mathrm{C}$ for $3-4$ days. The percentage of survival of these strains after UV irradiation was also determined; exponential phase cultures of all strains were harvested and pellets were re-suspended in $2 \mathrm{~mL}$ of $1 \times$ PBS. $200 \mu \mathrm{L}$ were exposed to UV intensities of $0,2,4$ and $6 \mathrm{~mJ} / \mathrm{cm}^{2}$ (as measured with a VLX $3 \mathrm{~W}$ dosimeter). Viable counts of the cultures were determined by plating serial dilution on LB plates with appropriate antibiotics after 4 days at $37^{\circ} \mathrm{C}$.

\section{Hydrogen peroxide assay}

M. smegmatis strains, were grown in triplicate in LBT medium up to stationary phase $\left(\mathrm{OD}_{600}=1.5\right)$. Cultures were serially diluted 1:100 in LBT supplemented with 0 and $5 \mathrm{mM} \mathrm{H}_{2} \mathrm{O}_{2}$ freshly prepared, placed in the microtiter well plates and incubated in a Bioscreen $\mathrm{C}$ kinetic growth reader at $37^{\circ} \mathrm{C}$ with constant shaking. Growth was monitored as $\mathrm{OD}_{600 \mathrm{~nm}}$ at $3 \mathrm{~h}$ intervals for $48 \mathrm{~h}$.

\section{Acknowledgements}

We would like to express a special acknowledgement to Dr. Jean-Marc Reyrat, a great microbiologist and a great person who loved life and his work, who unfortunately passed away before drafting the manuscript. We will never forget him. We thank L. Di lorio for technical assistance. We acknowledge Ivan Matic for allowing us to use the VLX $3 \mathrm{~W}$ dosimeter. We thank Ezio Ricca, Maurilio De Felice, Mario Varcamonti and Riccardo Manganelli for critical reading of the manuscript and suggestions. We are grateful to Emilia MF Mauriello for english revision of the manuscript. This work was supported by European Community's Sixth Framework Programme (Project number: LSHP-CT-2006-037566) to JMR

\section{Author details}

'Dipartimento di Biologia Strutturale e Funzionale, Università Federico II di Napoli, via Cinthia 4, 80126 Napoli, Italy. ${ }^{2}$ Inserm, U570, Unité de Pathogénie des Infections Systémiques, Paris Cedex 15, 156 rue de Vaugirard, 75015 Paris, France. ${ }^{3}$ Institut Pasteur, CNRS URA 2172, Unité de Génétique des Biofilms, 25-28 rue du Docteur Roux, 75724 Paris, France.

\section{Authors' contributions}

AC carried out most of the experiments, contributed to experimental design and draft the manuscript; BA carried out complementation experiments and UV assay; IC carried out oxidative stress experiment; DE carried out LM-PCR experiment; JMR conceived and supervised the study. All authors read and approved the final manuscript.

\section{Competing interests}

The authors declare that they have no competing interests.

Received: 16 June 2011 Accepted: 18 October 2011

Published: 18 October 2011

\section{References}

1. Manabe YC, Bishai WR: Latent Mycobacterium tuberculosis-persistence, patience, and winning by waiting. Nat Med 2000, 1327-1329.

2. Gomez JE, McKinney JD: $M$. tuberculosis persistence, latency, and drug tolerance. Tuberculosis 2004, 84:29-44.

3. Honer zu Bentrup K, Russel DG: Mycobacterial persistence: adaptation to a changing environment. TRENDS in Microbiology 2001.

4. Dick T, Lee BH, Murugasu-oei B: Oxygen depletion induced dormancy in Mycobacterium smegmatis. FEMS Microbiol Letters 1998, 162:159-164.
5. Lim A, Dick T: Plate-based dormancy culture system for Mycobacterium smegmatis and isolation of metronidazole-resistant mutants. FEMS Microbiol Letters 2001, 200:215-219.

6. Wayne LG, Hayes LG: An in vitro model for sequential study of shiftdown of Mycobacterium tuberculosis through two stages of non replicating persistence. Infect Immun 1996, 64:2062-2069.

7. Nyka W: Studies on the effect of starvation on mycobacteria. Infect Immun 1974, 9:843-850.

8. Loebel RO, Shorr E, Richardson HB: The influence of foodstuffs upon the respiratory metabolism and growth of human tubercle bacilli. J Bacterio/ 1933, 26:139-166.

9. Loebel RO, Shorr E, Richardson HB: The influence of adverse conditions upon the respiratory metabolism and growth of human tubercle bacilli. J Bacteriol 1933, 26:167-200.

10. Lim A, Eleuterio M, Hutter B, Murugasu-Oei B, Dick T: Oxygen depletion induced dormancy in Mycobacterium Bovis BCG. J Bacteriol 1999, 181:2252-2256.

11. Rustad TR, Sherrid AM, Minch KJ, Sherman DR: Hypoxia: a window into Mycobacterium tuberculosis latency. Cell Microbiol 2009, 11:1151-1159.

12. Smeulders MJ, Keer J, Speight RA, Williams HD: Adaptation of Mycobacterium smegmatis to stationary phase. J Bacteriol 1999, 181:270-283.

13. Sonden B, Kocincova D, Deshayes C, Euphrasie D, Rayat L, Laval F, Frahel C, Daffè M, Etienne G, Reyrat JM: Gap, a mycobacterial specific integral membrane protein, is required for glycolipid transport to the cell surface. Mol Microbiol 2005, 58:426-440.

14. Van Houten B, Croteau DL, DellaVecchia MJ, Wang H, Kisker C: "Closefitting sleeves": DNA damage recognition by the UvrABC nuclease system. Mutat Res 2005, 577:92-117.

15. Kurthkoti K, Varshney U: Base exision and nucleotide exision repair pathways in mycobacteria..

16. Darwin $\mathrm{KH}$, Nathan CF: Role for nucleotide excision repair in virulence of Mycobacterium tuberculosis. Infect Immun 2005, 73:4581-458.

17. Darwin $\mathrm{KH}$, Nathan CF: Role for nucleotide excision repair in virulence of Mycobacterium tuberculosis. Infect Immun 2005, 73:4581-458.

18. Kurthkoti K, Kumar $P$, Jain R, Varshney U: Important role of the nucleotide excision repair pathway in Mycobacterium smegmatis in conferring protection against commonly encountered DNA-damaging agents. Microbiology 2008, 154:2776-2785.

19. Guthlein C, Wanner RM, Sander P, Davis EO, Bosshard M, Jiricny J, Bottger EC, Springer B: Characterisation of the mycobacterial NER system reveals novel functions of uvrD1 helicase. J Bacteriol 2009, 191:555-562.

20. Sureka K, Dey S, Singh AK, Dasgupta A, Rodrigue S, Basu J, Kundu M: Polyphosphate kinase is involved in stress-induced mprAB-sigE-rel signalling in mycobacteria. Mol Microbiol 2007, 65:261-276.

21. Prod'hom G, Guilhot C, Gutierrez MC, Varnerot A, Gicquel B, Vincen V: Rapid discrimination of Mycobacterium tuberculosis complex strains by ligationmediated PCR fingerprint analysis. J Clin Microbio/ 1997, 35:3331-3334.

22. Berthet FX, Lagranderie M, Gounon P, Laurent-Winter C, Ensergueix D, Chavarot P, Thouron F, Maranghi E, Pelicic V, Portnoï D, Marchal G, Gicquel B: Attenuation of virulence by disruption of Mycobacterium tuberculosis erp gene. Science 1998, 282:759-762.

23. Adams LB, Dinauer MC, Morgenstern DE, Krahenbuhl JL: Comparison of the roles of reactive oxygen and nitrogen intermediates in the host response to Mycobacterium tuberculosis using transgenic mice. Tubercle Lung Dis 1997, 78:237-246.

24. Akaki T, Tomioka H, Shimizu T, Dekio S, Sato K: Comparative roles of free fatty acids with reactive nitrogenintermediates and reactive oxygen intermediates in expression of the anti-microbial activity of macrophages against Mycobacterium tuberculosis. Clin Exp Immunol 2000, 121:302-310.

25. Nathan C, Shiloh MU: Reactive oxygen and nitrogen intermediates in the relationship between mammalian hosts and microbial pathogens. $P$ Natl Acad Sci USA 2000, 97:8841-8848.

26. Lau YL, Chan GC, Ha SY, Hui YF, Yuen KY: The role of the phagocytic respiratory burst in host defense against Mycobacterium tuberculosis. Clin Infect Dis 1998, 26:226-227.

27. Wang CH, Liu CY, Lin HC, Yu CT, Chung KF, Kuo HP: Increased exhaled nitric oxide in active pulmonary tuberculosis due to inducible NO synthase upregulation in alveolar macrophages. Eur Respir J 1998, 11:809-815. 
28. Mizrahi V, Andersen SJ: DNA repair in Mycobacterium tuberculosis. What have we learnt from the genome sequence? Mol Microbiol 1998, 29:1331-1339

29. Springer B, Sander P, Sedlacek L, Hardt WD, Mizrahi V, Schär P, Böttger EC: Lack of mismatch correction facilitates genome evolution in mycobacteria. Mol Microbiol 2004, 53:1601-1609.

30. Hiriyanna KT, Ramakrishnan T: Deoxyribonucleic acid replication time in Mycobacterium tuberculosis H37 Rv. Arch Microbiol 1986, 144:105-109.

31. Dos Vultos T, Mestre O, Tonjum T, Gicquel B: DNA repair in Mycobacterium tuberculosis revisited. FEMS 2009.

32. Demple B, Harrison L: Repair of oxidative damage to DNA: enzymology and biology. Annu Rev Biochem 1994, 63:915-948.

33. Neeley WL, Essigmann JM: Mechanisms of formation, genotoxicity, and mutation of guanine oxidation products. Chem Res Toxicol 2006, 19:491-505.

34. David SS, O'Shea VL, Kundu S: Base-excision repair of oxidative DNA damage. Nature 2007, 447:941-950.

35. Snapper SB, Melton RE, Mustafa S, Kieser T, Jacobs WR Jr: Isolation and characterization of efficient plasmid transformation mutants of Mycobacterium smegmatis. Mol Microbiol 1990, 4:1911-1919.

36. Sambrook J, Fitsch EF, Maniatis T: Molecular Cloning: A Laboratory Manual Cold Spring Harbor, Cold Spring Harbor Press; 1989.

37. Pelicic V, Reyrat JM, Gicquel B: Generation of unmarked directed mutations in mycobacteria, using sucrose counter-selectable suicide vectors. Mol Microbiol 1996, 20:919-925.

38. de Mendonca-Lima L, Picardeau M, Raynaud C, Rauzier J, de la salmoniere YO, Barker L, Bigi F, Cataldi A, Gicquel B, Reyrat JM: Erp, an extracellular protein family specific to mycobacteria. Microbiology 2001, 147:2315-2320.

39. Vultos TD, Mederle I, Abadie V, Pimentel M, Moniz-Pereira J, Gicquel B, Reyrat JM, Winter N: Modification of the mycobacteriophage Ms6 attP core allows the integration of multiple vectors into different tRNAala Tloops in slow- and fast-growing mycobacteria. BMC Mol Biol 2006, 7:47.

doi:10.1186/1471-2180-11-231

Cite this article as: Cordone et al: Characterization of a Mycobacterium smegmatis uvrA mutant impaired in dormancy induced by hypoxia and low carbon concentration. BMC Microbiology 2011 11:231.

\section{Submit your next manuscript to BioMed Central and take full advantage of:}

- Convenient online submission

- Thorough peer review

- No space constraints or color figure charges

- Immediate publication on acceptance

- Inclusion in PubMed, CAS, Scopus and Google Scholar

- Research which is freely available for redistribution

Submit your manuscript at www.biomedcentral.com/submit
Biomed Central 